\title{
Effect of Optical Radiation on the Properties of Gamma Radiated Silicate Glass
}

\author{
Rajabboy T. Khaydarov1, Holida B. Beisinbaeva1, Golibjon R. Berdiyorov², \\ Ravshan R. Khaydarov ${ }^{1}$ \\ ${ }^{1}$ Institute of Applied Physics, National University of Uzbekistan, Tashkent, Uzbekistan \\ ${ }^{2}$ Qatar Environment and Energy Research Institute, Doha, Qatar \\ Email: rtkhaydarov@yahoo.com.ph
}

Received 22 January 2014; revised 18 February 2014; accepted 15 March 2014

Copyright (C) 2014 by authors and Scientific Research Publishing Inc.

This work is licensed under the Creative Commons Attribution International License (CC BY). http://creativecommons.org/licenses/by/4.0/

c) (i) Open Access

\begin{abstract}
We study the effect of intense laser radiation on the surface of silicate glass prior irradiated by gamma radiation. Experimental results show that the gamma radiation with dose $5 \times 10^{4} \mathrm{R}$ leads to the degradation of the surface resistance of this optical dielectric to electromagnetic radiation. Depending on the dose of the radiation the laser radiation can result in either surface erosion or its pronounced cracking. It is also found that the efficiency of the degradation process is determined not only by the radiation dose, but also by the presence of different impurities in the glass.
\end{abstract}

\section{Keywords}

Laser-Induced Plasma, Multi-Charge Ions, Mass-Spectrometer

\section{Introduction}

Optical materials, in particular silicate glass, are used in different experimental conditions with the increased dose of radiation [1]. The resistance of such optical dielectrics to electromagnetic radiation has received a lot of attention after creation of powerful lasers and their application in broad area of science and technology. Examples are the applications of lasers in modern laser sources of ions and their implementation in diagnostics systems [2]-[8]. For example, high purity silicas are being considered as the main candidate materials for use as windows and optical components (lenses, optical fibres) for diagnostics and remote handling systems in International Thermonuclear Experimental Reactor due to their radiation hardness (see, e.g., Ref. [9] and references therein). A number of studies in the past have been devoted to the damage of these materials by the laser radiation (see, e.g., Ref. [10]). It was found that the latter process can have either surface or volume character. Depending on the intensity of the laser radiation (q) the interaction can result in "peeling" of the surface of the opt- 
ical dielectric or in its dramatic cracking [11]-[14]. It was also found that different dynamical (e.g., lattice vibrations, density fluctuations) and static (impurities and inclusions) inhomogeneities can lead to different nonlinear effects, including self-focusing. However, the dependence of the efficiency of the process of optical damage of the silicate glass on the intensity of the laser radiation, as well as on the structural properties of the material itself (i.e. the presence of certain non-controllable or especially included inclusion) still requires additional research.

\section{Experimental Method}

In this work we study the effect of gamma-radiation-created-defects on the interaction of laser radiation with the surface of silicate glass. The intensity of the neodymium glass laser, working in single shoot mode, was calibrated in the interval of $\mathrm{q}=10^{8}-10^{11} \mathrm{~W} / \mathrm{cm}^{2}$ using optical filters. We found that the presence of a layer of adsorbed gas atoms, water and dust results in error in determining the optical resistance of the material. To avoid this we have placed the sample in a vacuum condition $\sim 10^{-6}$ Torr. We first cleaned the surface of the sample using the laser radiation with small intensity. We used optical microscopy and spectroscopy to study the processes of the surface damage.

It is known that the damage threshold of the optical dielectrics is above $10^{9} \mathrm{~W} / \mathrm{cm}^{2}$. Since this value exceeds the threshold for the formation of laser-produced plasma $\left(\sim 10^{8} \mathrm{~W} / \mathrm{cm}^{2}\right)$, we combined the results of optical microscopy with the results of laser mass-spectrometry, where we study the properties of the plasma ions. This allows us to study not only the morphology of the surface destruction, but also to determine the target composition, as well as the inclusions which results in degradation of the optical resistance of the glass. Schematics of our experimental setup is shown in Figure 1 (see, Ref. [15] for more information about the setup and the study method). In addition, these initial experimental conditions were close to the conditions that exist in the actual use of laser ion sources: the combined impact of intense laser radiation and the formation of high-temperature plasma products.

The radiation from the $\mathrm{Nd}^{3+}$ glass laser with wavelength $1060 \mathrm{~nm}$ and pulse duration $50 \mathrm{~nm}$ has been focused on the surface of the target within the area of $250 \mu \mathrm{m}$ in diameter. As the threshold intensity $\mathrm{q}_{\mathrm{c}}$ for destruction of the target was used the value of $\mathrm{q}$ which corresponds to high-temperature shining and formation of dense plasma. To avoid the effect of accumulation [16]-[19], the interaction place of laser radiation with the target was changed after the formation of laser-produced plasma. The destruction damage is obtained when the ion signals appear in the mass-spectra. The targets were made in the form of desks with thickness $2 \mathrm{~mm}$. As the cleanliness of the sample surface determines the resistance of the target to the radiation, the surface of the sample is cleaned before every measurement.

\section{Experimental Results}

Microscopic analysis of the target surface shows that the damage of the surface by the laser radiation occurs in

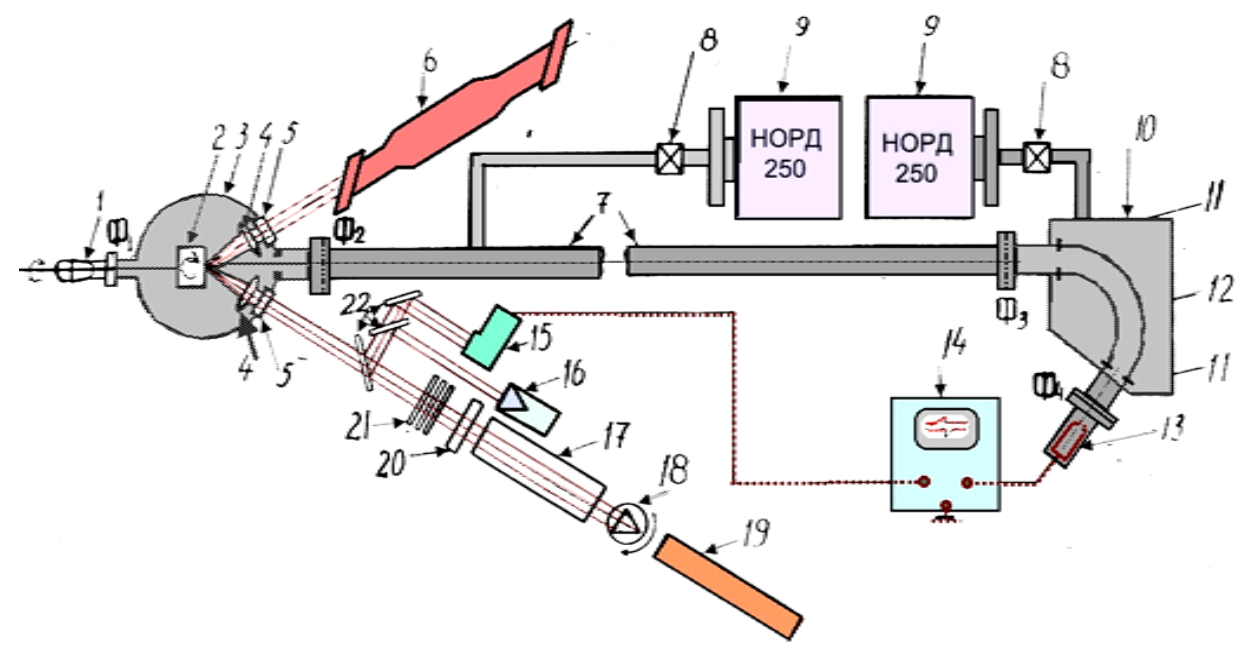

Figure 1. Schematics of the experimental setup. 3: multifunctional target chamber, 7: timeof-flight mass-analyzer, 12: electrostatic analyzer, 13: ions detector, 17: Nd:YAG laser, 18: modulator, 11: parallel plates, 22: mirrors, 4: focusing lenses, 16: calorimeter, 14: scillograph. 
the form of craters with molten edges, inside of which there are small cavities. The reason for the formation of these microcraters is the presence of impurity inclusions and optical inhomogeneities, which result in effective adsorption of laser energy [20]. This model gives the value of the threshold intensity $\mathrm{q}_{\mathrm{c}}=7 \times 10^{9} \mathrm{~W} / \mathrm{cm}^{2}$ for the glass type GLS-1. In this sample the diameter of the crater was $\sim 50 \mu \mathrm{m}$. The size of the crater increases with further increasing the intensity of the laser $\mathrm{q}$, and it reaches $\sim 300 \mu \mathrm{m}$ for $\mathrm{q}=100 \mathrm{GW} / \mathrm{cm}^{2}$.

Similar crater formation has been reported previously by one of the authors [21]. Analysis of the mass-spectra of the plasma formed during the destruction of this glass by the laser, shows that there are additional non-controllable inclusions in the sample. The following elements have been observed in the spectra: $\mathrm{H}, \mathrm{O}, \mathrm{C}$ and Fe. The existence of hydrogen and oxygen in the plasma indicates to the presence of water and other hydroxyl groups in the glass [15] and the other elements could be included into the target during the technological processing of glass.

We start with determining the discharge of impurity inclusions during the laser interaction. We found that the amplitude of the signal in the spectra corresponding to particular element depends on the intensity of the laser radiation. For example, peaks corresponding to $\mathrm{C}$ and Fe appear in the mass-spectra starting at $\mathrm{q}=\mathrm{q}_{\mathrm{c}}$ together with the elements of the crystal lattice of the target [see Figure 2(a), Figure 2(b)]. With increasing q additional peaks appear in the mass-spectra correspond to the other elements [Figures 2(c)-(f)]. Since only signals of C and $\mathrm{Fe}$ appear in the signal at $\mathrm{q}=\mathrm{q}_{\mathrm{c}}$ we can assume that these elements reduce the optical conductivity of the system. This assumption is based on the fact that the destruction starts at a certain, isolated point. In addition, analysis of the data on the optical resistance of the GLS glass with different concentration of Fe shows that with increasing the concentration of this inclusion results not only in the reduction of $\mathrm{q}_{\mathrm{c}}$ but also in the increase of the amount of cavities. In these experimental conditions, one of the reasons for the reduction of $\mathrm{q}_{\mathrm{c}}$ in samples with larger concentration of Fe is connected with additional adsorption in wide range with maximum near 900 - 950 $\mathrm{nm}$. This additional adsorption appears in the spectrum of the optical adsorption of clean sample with introducing Fe ions.

Next, we consider the effect of Nd doping of GLS glass on its resistance to laser radiation. We found experimentally that $\mathrm{q}_{\mathrm{c}}$ decreases monotonically with increasing the concentration of $\mathrm{Nd}$ ions (see Figure 3). For example, $\mathrm{q}_{\mathrm{c}}$ drops from $7.2 \times 10^{9} \mathrm{~W} / \mathrm{cm}^{2}$ to $2.1 \times 10^{9} \mathrm{~W} / \mathrm{cm}^{2}$ with including $6 \%$ of $\mathrm{Nd}$. To our understanding, this reduction of $\mathrm{q}_{\mathrm{c}}$ is due to optical inhomogeneities created due to the fluctuations in the glass density, as well as due to the appearance of additional bands connected with the adsorption of $\mathrm{Nd}^{3+}$ ions.

We also study the resistance of GLS glasses on laser radiation when the sample irradiated by gamma radiation from $\mathrm{Co}_{60}$ sources with dose in the range of $10^{4}-5 \times 10^{10} \mathrm{R}$. Experimental results on the effect of gamma radiation show the followings (see Figure 4): 1) the spectrum of optical adsorption and the threshold value of the laser radiation $\mathrm{q}_{\mathrm{c}}$ are not affected for radiation of dose $\mathrm{D} \leq 5 \times 10^{4} \mathrm{R}$; 2) with increasing $\mathrm{D}>5 \times 10^{4} \mathrm{R}$ the color of the glasses changes and its optical resistance decreases. The intensity of these processes depends of the radiation dose. For example, with increasing the dose from $5 \times 10^{4} \mathrm{R}$ to $10^{9} \mathrm{R}$ results in the decrease of $\mathrm{q}_{\mathrm{c}}$ from $7.2 \times 10^{9}$ $\mathrm{W} / \mathrm{cm}^{2}$ to $10^{9} \mathrm{~W} / \mathrm{cm}^{2}$.

Thus, the critical intensity of the laser radiation $\mathrm{q}_{\mathrm{c}}$ depends on both the concentration of $\mathrm{Nd}$ ions and the dose of the gamma radiation, as shown in Figure 4. It is seen from this figure that $\mathrm{q}_{\mathrm{c}}$ decreases with increasing both the Nd concentration and dose of the gamma radiation. We found out from the studies of the optical absorption of the silicate glass that inovolent transition in $\mathrm{Nb}$ will not occur for the dose up to $5 \times 10^{10} \mathrm{R}$. However, total background in the interval of active absorption of $\mathrm{Nd}^{3+}$ and the range of laser interaction increases.

In order to increase optical resistance of the glasses for the interacting ionizing radiation, we included $\mathrm{Ce}^{3+}$ ions into the sample. Experimental results show that co-activation of clean GLS glasses with these ions increases optical resistance of the sample with our without gamma radiation. We also found out that cerium inclusion for the Nd doped samples does not affect the value of $\mathrm{q}_{\mathrm{c}}$. In gamma radiated samples the size of the cracks is smaller in Ce doped samples that the ones for Nd included samples. For example, the size of the surface destruction of $2 \% \mathrm{Nd}$ doped samples at $\mathrm{q}=10^{9} \mathrm{~W} / \mathrm{cm}^{2}$ decreases from $30 \%$ to $10 \%$ with including Ce with concentration in the range of $0.3 \%$ to $3.2 \%$.

However, noncontrollabe Fe inclusions have opposite effect: optical resistance of non Ce activated targets decreases with increasing the concentration of Fe. It also increases the size of the main crater and the cavities as well. Gamma irradiation further increases the effect of Fe inclusions. The analysis of adsorption spectra of the glasses shows that gamma radiation results in strong coloring of the samples, increased background adsorption in the range of $850-1200 \mathrm{~nm}$ and appearance of additional intense gap in the absorption with a maximum at 


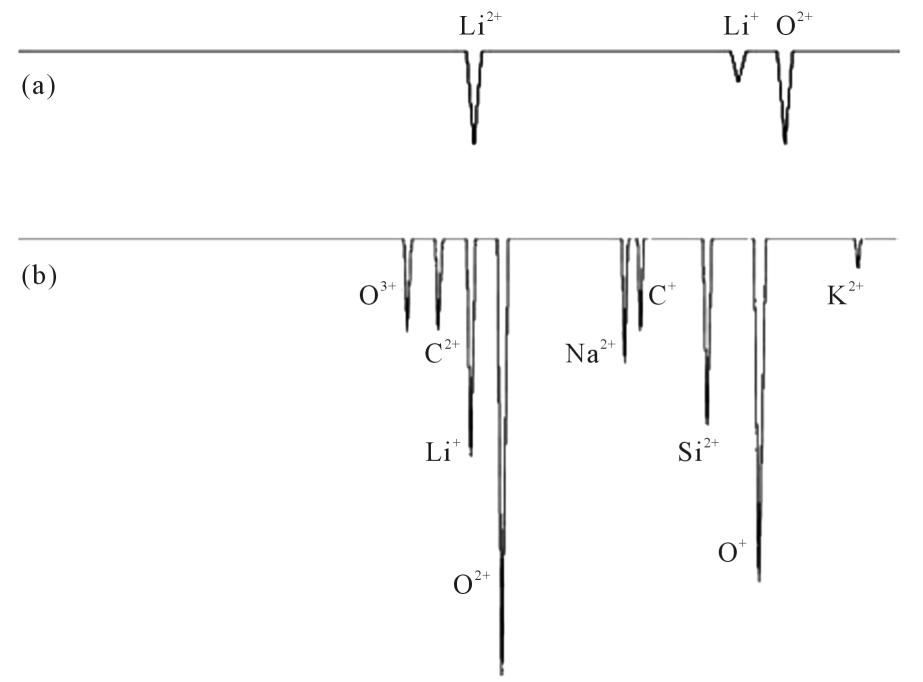

(c)

$$
\mathrm{Fe}^{+}
$$

(d)

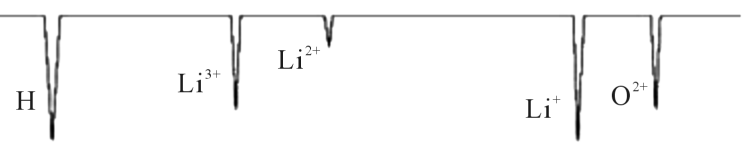

(e)
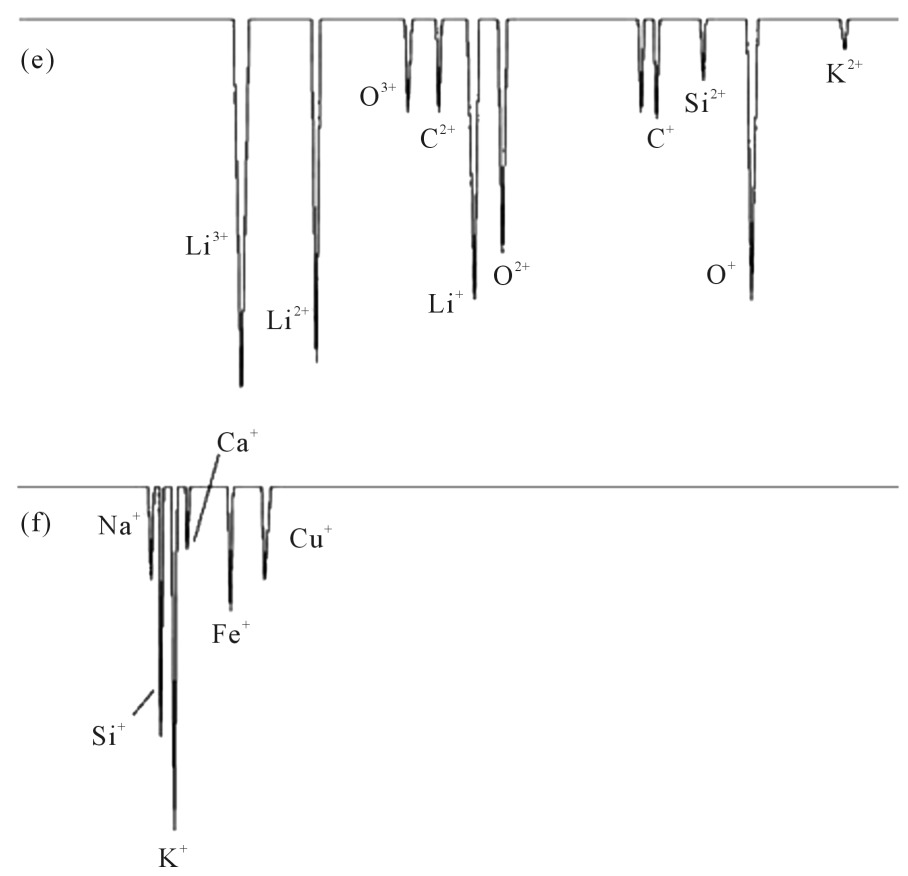

Figure 2. Mass-spectra of plasma generated on the surface of silicate glass during the interaction of laser radiation with intensities $q=7 \times$ $10^{9}$ (a)-(c) and $\mathrm{q}=9 \times 10^{9} \mathrm{~W} / \mathrm{cm}^{2}$ (d)-(f). The energies of the ions are $\mathrm{E} / \mathrm{z}=50 \mathrm{eV}$ ((a), (d)), $800 \mathrm{eV}$ ((b), (e)) and $2000 \mathrm{eV}$ ((c), (f)). 


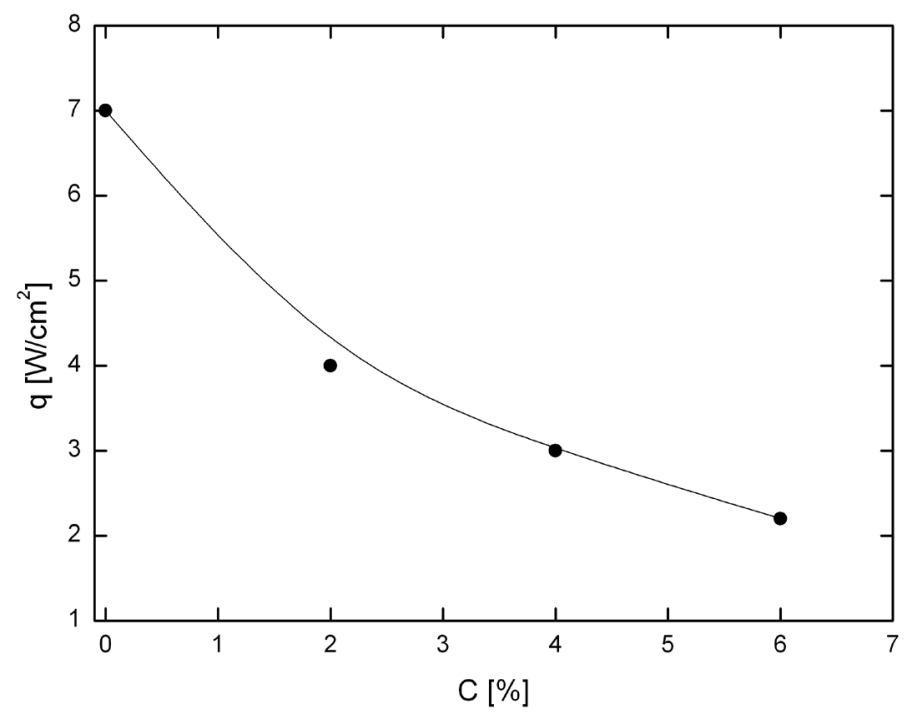

Figure 3. Dependence of the intensity of laser radiation $\left(\times 10^{9}\right)$ corresponding to the surface destruction of the glass samples on the concentration of $\mathrm{Nd}$ ions.

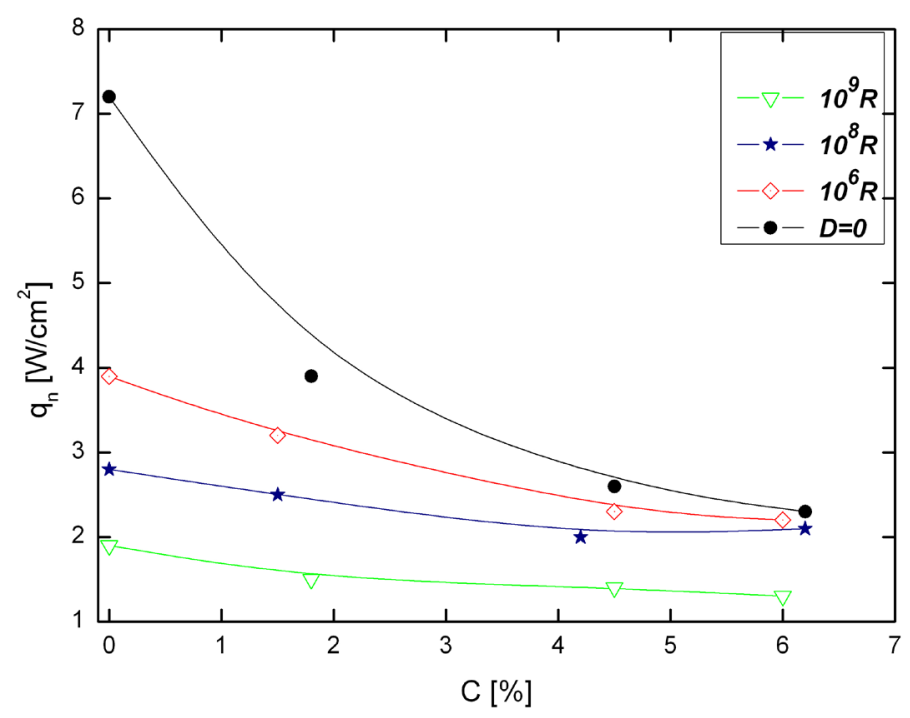

Figure 4. The critical intensity of the laser radiation $\left(\times 10^{9}\right)$ corresponding for the surface destruction of the glass sample as a function of Nd concentration. The results are shown for different values of the gamma-radiation dose.

$1100 \mathrm{~nm}$. The gap at $1100 \mathrm{~nm}$ increases with increasing the concentration of Fe. For example, the absorption in the range of $1100 \mathrm{~nm}$ increases 1.5 and 1.8 times with including $10^{-3} \%$ and $10^{-2} \%$ of Fe into the sample after gamma irradiation. With increases the dose of the irradiation above $\mathrm{D}>10^{8} \mathrm{R}$ additional gap appeared in the optical spectra with maximum at $215 \mathrm{~nm}$. Its intensity increases with increasing the radiation dose.

Analysis of the data about the effect of gamma irradiation on the critical laser intensity $\mathrm{q}_{\mathrm{c}}$ shows one characteristical feature for both clean and doped samples: monotonic decrease of $\mathrm{q}_{\mathrm{c}}$ and increase of the size of the craters occur only for doses $\mathrm{D}=10^{8} \mathrm{R}$. At higher doses the intensity of surface destruction and degradation of $\mathrm{q}_{\mathrm{c}}$ further increases. The destruction is correlated with the appearance of additional adsorption gaps in the optical spectrum of gamma-irradiated samples with maximum at $215 \mathrm{~nm}$. Intensity of this gap is proportional to the dose of radiation and becomes more pronounced for the does above $10^{9} \mathrm{R}$. 
Strong cracking of the sample surface is observed for the doses above $10^{10} \mathrm{R}$. The destruction occurs in the form of a large crater with smaller ones inside it. The main crater is surrounded by a set of cracks of different width and depth. The critical laser intensity of the glasses containing Fe is always smaller than the one for Ce doped samples. For example, for the sample including $5.6 \% \mathrm{Nd}$ and $10^{-2} \% \mathrm{Fe}$ the cracking starts at $\mathrm{q}_{\mathrm{c}}=10^{10}$ $\mathrm{W} / \mathrm{cm}^{2}$ and decrease of the Fe concentration to $10^{-3} \%$ increases the $\mathrm{q}_{\mathrm{c}}$ up to $2.8 \times 10^{10} \mathrm{~W} / \mathrm{cm}^{2}$. With including Ce and increasing its concentration from $0.3 \%$ to $2 \%$ results in increase of $\mathrm{q}_{\mathrm{c}}$ from $4 \times 10^{10}$ to $8 \times 10^{10} \mathrm{~W} / \mathrm{cm}^{2}$. In these experimental conditions $\mathrm{q}_{\mathrm{c}}$ of the clean sample was $10^{11} \mathrm{~W} / \mathrm{cm}^{2}$.

\section{Discussions}

To the best of our knowledge, the negative role of Fe ions on the resistance and optical absorption of gamma radiated glasses can be explained as follows. It is well knows that Fe can exists in glasses in different forms. The appearance of additional gap in the adsorption spectra of the sample with maximum at $1100 \mathrm{~nm}$ and increase of its intensity with increasing the radiation indicates to the fact that gamma radiation results in inovalent transition of $\mathrm{Fe}$ ions, i.e., $\mathrm{Fe}^{3+}$ ions capture additional electron during the irradiation and forms $\mathrm{Fe}^{2+}$ [16] [17], which adsorbs the radiation at $1100 \mathrm{~nm}$. As the wavelength of the laser radiation is $1060 \mathrm{~nm}$, the formation of defects in the sample which adsorbs this radiation, should lead to increase of efficiency of the degradation process of light resistance of gamma-radiated glasses.

It was found experimentally that the degradation process of light resistance of gamma-irradiated glasses can be slowed down by including Ce ions. The analysis of optical adsorption spectra of non Ce activated sample show that gamma radiation results in formation of defects which absorb the electromagnetic radiation in UV, optical and infrared range of the spectra. The high temperature plasma, generated during the interaction of laser radiation is an effective source of optical radiation covering all the optical part of the spectra. The formation of defects in gamma-radiated sample results in addition heating of the sample and promotes initial destruction. Introducing of Ce during the gamma radiation affects the electron capturing process of the other defects. This results in decrease of the defect formation process, which can absorb the laser radiation in addition to plasma radiations. To our knowledge, this can explain the experimental fact that the presence of Ce ions results in reduction $\mathrm{f}$ the surface destruction.

We also found that independently on the type and concentration of the inclusions, there is a change in the dependence of $\mathrm{q}_{\mathrm{c}}$ on the dose of radiation for $\mathrm{D} \geq 3 \times 10^{8} \mathrm{R}$. This change is correlated with the formation of additional gaps in the optical spectra of adsorption of gamma-irradiated sample with maximum of $215 \mathrm{~nm}$. This is connected by the formation of additional centers which adsorbs in this range (i.e., E-centers) [18]. This center is the electron captured by the vacancy sites of oxygen [19]. The formation of such defects in the glass indicates to the formation of structural defects for the doses above $\mathrm{D} \geq 3 \times 10^{8} \mathrm{R}$. The intensity of this process, which is connected with the bond breaking between silicon-oxygen and the distortion of the first coordination sphere of the ion-glass former [19], increases with increasing the radiation dose. As a result of structural defect formation process and formation of oxygen vacancies, uniform distribution of the potential energy of the glass matrix changes [20]. Coulomb forces distort the bonds between silicon and oxygen. The tension formed in this process leads to the increase of the degradation process of sample surface strength. The increase of the concentration of E-centers, which take place at doses $\mathrm{D} \geq 3 \times 10^{8} \mathrm{R}$, results in sharp drop in $\mathrm{q}_{\mathrm{c}}$ and dramatic destruction of the surface of the optical dialectic takes place.

\section{Conclusion}

Using the mass-spectrometric method we study the effect of gamma radiation, as well as the effect of metallic inclusions on the absorption properties and light resistance of silicate glasses. Depending on the dose of the gamma radiation, the surface resistance of the samples to the laser radiation decreases considerably due to the surface erosion or crack formation. Different metallic inclusions (Fe or Ce) further decrease the resistance of the glasses as these inclusions become centers of intense light absorption.

\section{References}

[1] Decreton, M., Shikama, T. and Hodson, E. (2004) Journal of Nuclear Materials, 329, 125. http://dx.doi.org/10.1016/j.jnucmat.2004.04.012

[2] Brichard, B., Fernandez, A., Ooms, H., et al. (2004) Journal of Nuclear Materials, 329, 1456. 
http://dx.doi.org/10.1016/j.jnucmat.2004.04.159

[3] Girard, S., Marcandella, C., Morana, A., et al. (2013) IEEE Transactions on Nuclear Science, 60, 4305. http://dx.doi.org/10.1109/TNS.2013.2281832

[4] Gusarov, A. and Hoeffgen, S.K. (2013) IEEE Transactions on Nuclear Science, 60, 2037. http://dx.doi.org/10.1109/TNS.2013.2252366

[5] Girard, S., Kuhnhenn, J., Gusarov, A., et al. (2013) IEEE Transactions on Nuclear Science, 60, 2015. http://dx.doi.org/10.1109/TNS.2012.2235464

[6] Islamov, A., Salikhbaev, U.S., Ibragimova, E.M., et al. (2013) Journal of Nuclear Materials, 443, 393. http://dx.doi.org/10.1016/j.jnucmat.2013.07.027

[7] Sporea, D., Sporea, A. and Oproiu, C. (2013) Optical Fiber Technology, 19, 652. http://dx.doi.org/10.1016/j.yofte.2013.10.005

[8] Kher, S., Chaubey, S., Oak, S.M., et al. (2013) IEEE Photonics Technology Letters, 25, 2070. http://dx.doi.org/10.1109/LPT.2013.2281200

[9] Martín, P., León, M., Ibarra, A. and Hodgson, E.R. (2011) Journal of Nuclear Materials, 417, 818. http://dx.doi.org/10.1016/j.jnucmat.2010.12.171

[10] Martin, P., Morono, A. and Hodgson, E.R. (2004) Journal of Nuclear Materials, 329, 1442. http://dx.doi.org/10.1016/j.jnucmat.2004.04.162

[11] De Temmerman, G., Pitts, R.A., Voitsenya, V.S., et al. (2007) Journal of Nuclear Materials, 363, 259. http://dx.doi.org/10.1016/j.jnucmat.2007.01.024

[12] Khaydarov, R.T., Beisinbaeva, H.B., Sabitov, M.M., Terentev, V.B. and Tojinazarov, F.M. (2009) Nuclear Fusion, 49, Article ID: 065022. http://dx.doi.org/10.1088/0029-5515/49/6/065022

[13] Danileyko, Yu.K., Matyushin, G.A. and Nechitaylo, V.S. (1983) Russian Journal Quantum Electronics, $10,721$.

[14] Danileyko, Yu.K., Manenkov, A.A., Nechitaylo, V.S. and Ritus, A.I. (1984) Russian Journal Quantum Electronics, 11, 1812.

[15] Brichard, B., Tomashuk, A.L., Bogatyrjov, V.A., et al. (2007) Journal of Non-Crystaline Solids, 353, 466. http://dx.doi.org/10.1016/j.jnoncrysol.2006.10.039

[16] Turdiev, T.T., Ibragimov, J.D. and Nuritdinov, I. (2005) Uzbek Journal of Physics, 7, 105.

[17] Burjinskii, I.M., Avakyants, L.I. and Surkova, V.F. (1975) Russian Journal of Applied Spectroscopy, 22, 248.

[18] Feigl, F.J., Fowler, D. and Yip, K.H. (1974) Solid State Communications, 14, 225. http://dx.doi.org/10.1016/0038-1098(74)90840-0

[19] Brekhovskikh, S.M., Tyul'nin, V.A. and Mamedov, E.K. (1987) Russian Journal of Physics and Chemistry of Glasses, 4, 443.

[20] Islamov, A.Kh., Ibragomova, E.M. and Nuritdinov, I. (2007) Journal of Nuclear Materials, 363, 1023.

[21] Beisinbaeva, H.B., Sabitov, M.M., et al. (2004) The 3rd Eurasian Conference "Nuclear Science and Its Application", Tashkent, 5-8 October 2004. 
Scientific Research Publishing (SCIRP) is one of the largest Open Access journal publishers. It is currently publishing more than 200 open access, online, peer-reviewed journals covering a wide range of academic disciplines. SCIRP serves the worldwide academic communities and contributes to the progress and application of science with its publication.

Other selected journals from SCIRP are listed as below. Submit your manuscript to us via either submit@scirp.org or Online Submission Portal.
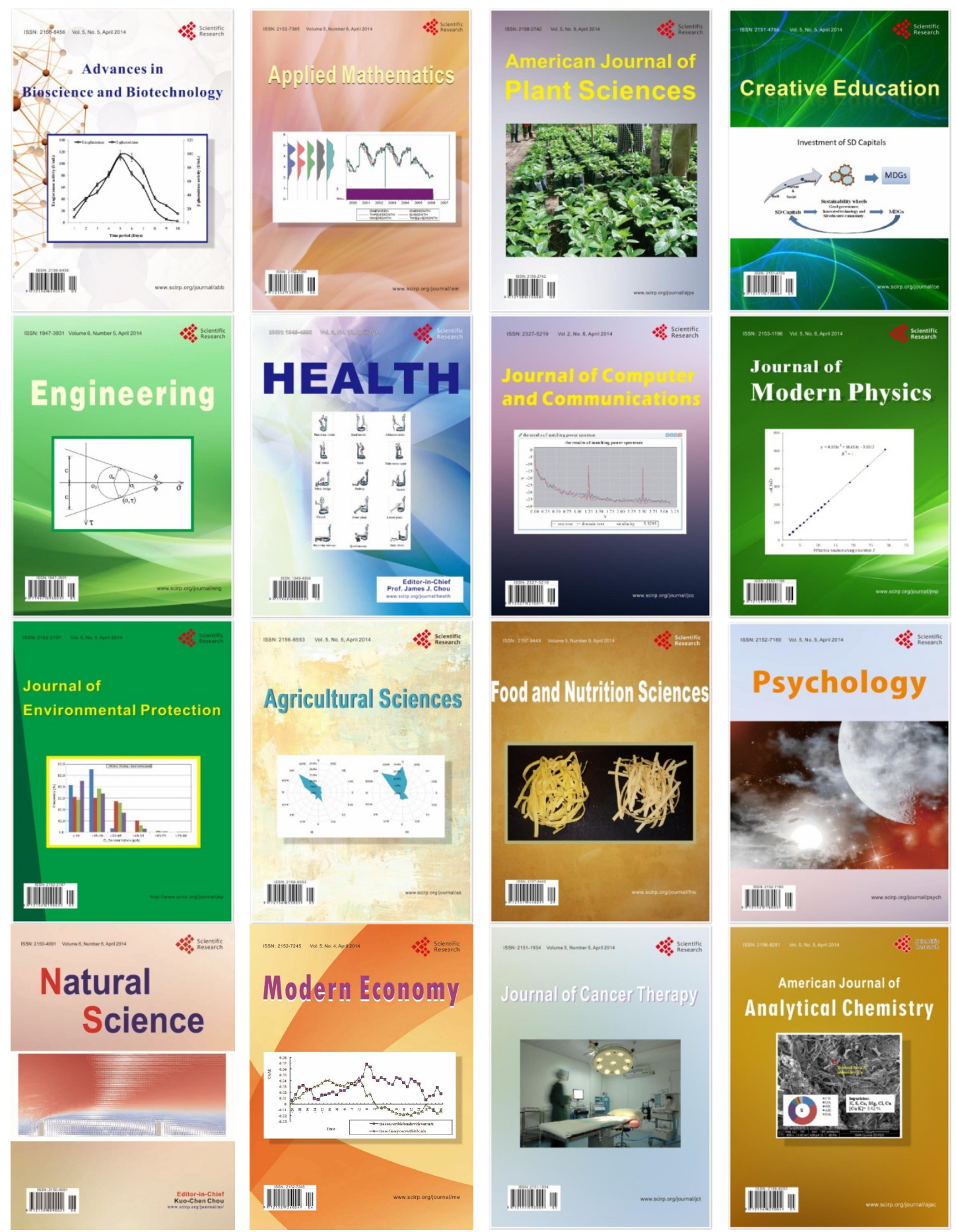